\title{
Effects of oxytocin and uterine and luteal prostaglandins on the functional regression of the corpus luteum in pseudopregnant rats
}

\author{
L. Cao and W. Y. Chan* \\ Department of Pharmacology, Cornell University Medical College, New York, NY 10021, USA
}

\begin{abstract}
The effects of oxytocin on luteal regression in the pseudopregnant rat and whether the luteolytic effect of oxytocin could be blocked by an oxytocin receptor antagonist were investigated. We determined the temporal relationship between the effects of oxytocin on the duration of pseudopregnancy and concentrations of progesterone in plasma, and uterine and luteal prostaglandin concentrations. Pseudopregnancy was induced in normal cyclic rats by gonadotrophin treatment. On day 6 of pseudopregnancy, rats were assigned to one of three groups. One group was given oxytocin, $500 \mathrm{mU}$ s.c., twice a day for three days. A control group was given saline injections. A third group was given the same dose of oxytocin and an oxytocin receptor antagonist, $\left[\mathrm{Pen}^{1}\right.$, Phe $(\mathrm{Me})^{2}$, $\left.\mathrm{Thr}^{4}, \mathrm{Orn}^{8}\right]$ oxytocin, $300 \mu \mathrm{g}$ day $^{-1}$, delivered by micro-osmotic pumps for the same three-day period. Rats were either observed to determine the duration of pseudopregnancy, or killed on days $2,6,7,9,11$ and 13 of pseudopregnancy for measurements of plasma concentrations of progesterone and luteal and uterine $\mathrm{PGF}_{2 \alpha}$ and $\mathrm{PGE}_{2}$ concentrations by radioimmunoassays. Oxytocin injections shortened the duration of pseudopregnancy from the mean of $13.5 \pm 0.3$ days for the control group to $11.5 \pm 0.3$ days for the oxytocin-treated group $(P<0.01)$. The oxytocininduced shortening of pseudopregnancy was associated with a premature functional regression of the corpus luteum. Both luteal and uterine $\mathrm{PGF}_{2 \alpha}$ concentrations were found to increase with luteolysis and reached peak values before the return of oestrus. However, only uterine $\mathrm{PGF}_{2 \alpha}$ synthesis was stimulated by oxytocin treatment. There was no significant increase in uterine or luteal $\mathrm{PGE}_{2}$ synthesis during luteolysis. The effect of oxytocin on shortening the duration of pseudopregnancy was blocked by the co-administration of the oxytocin receptor antagonist. Thus, our findings show that oxytocin is luteolytic in pseudopregnant rats. The close temporal association between oxytocin-induced functional luteal regression and oxytocin-stimulated uterine prostaglandin production suggests that the oxytocin-induced luteolysis is mediated via uterine $\mathrm{PGF}_{2 \alpha}$ as has been shown in domestic ruminants. The luteolytic action of oxytocin was mediated by the oxytocin receptor, as it was blocked by a specific oxytocin receptor antagonist.
\end{abstract}

\section{Introduction}

There is substantial evidence linking oxytocin to luteolysis in large domestic ruminants (Flint and Sheldrick, 1983; and reviews: Richardson, 1986; Silvia et al., 1991; Bazer, 1992). It is generally considered that ovarian oxytocin secreted by the corpus luteum is the endogenous oxytocin involved in luteolysis (Flint and Sheldrick, 1983; Wathes, 1984; Flint et al., 1990). The luteolytic action of oxytocin depends on a functioning uterus. It is thought that luteal oxytocin stimulates the secretion of $\mathrm{PGF}_{2 \alpha}$ from the uterus which is responsible for the luteolysis (Flint and Sheldrick, 1983; Flint et al., 1990). PGF $_{2 \alpha}$ also stimulates oxytocin secretion from the corpus luteum (Flint and Sheldrick, 1982; Watkins and Moore, 1987; Lamsa et al., 1989). Because endogenous pulses of $\mathrm{PGF}_{2 \alpha}$ occur synchronously with pulses of oxytocin during luteolysis, it has been suggested that luteal ${ }^{*}$ Correspondence.

Received 10 November 1992. oxytocin and uterine $\mathrm{PGF}_{2 \alpha}$ exist in a positive feedback loop (Fairclough et al., 1980, 1984; Webb et al., 1981; Hooper et al., 1986; Moore et al., 1986; Flint et al., 1990). This positive feedback loop or the uterine prostaglandin secretory response to oxytocin becomes functional only late in the oestrous cycle, leading to luteolysis (Fairclough et al., 1984; Silvia and Taylor, 1989; Silvia et al., 1992). A similar luteolytic mechanism has also been reported in pigs (Kieborz et al., 1991).

The corpus luteum of humans and rats also synthesizes PGF $_{2 \alpha}$ (Challis et al., 1977; Swanston et al., 1977; Weems, 1979). The relative importance of the uterine and luteal prostaglandin components in luteal maintenance has not been elucidated. In pregnant and pseudopregnant rats, a high correlation between luteal PGF ${ }_{2 \alpha}$ contents and the demise of luteal function has been reported, suggesting a role for luteal $\mathrm{PGF}_{2 \alpha}$ in luteolysis at least in rats (Olofsson and Selstam, 1988; Olofsson et al., 1990).

It has not been shown whether oxytocin is luteolytic in rats. It has also not been shown whether the luteolytic action of 
oxytocin is mediated by the classical oxytocin receptors and could be blocked by specific oxytocin receptor antagonists. In the study reported here we determined whether oxytocin caused functional regression of the corpus luteum in pseudopregnant rats, investigated the temporal relationships between oxytocin-induced luteolysis and luteal and uterine prostaglandin production, and determined whether oxytocin-induced luteolysis can be blocked by a specific oxytocin receptor antagonist. Preliminary results of this study were reported at the 24th Annual Meeting of the Society for the Study of Reproduction, Vancouver, Canada (1991).

\section{Materials and Methods}

\section{Materials}

The oxytocin antagonist used was $\left[\mathrm{Pen}^{1}{ }^{1} \mathrm{Phe}(\mathrm{ME})^{2}, \mathrm{Thr}^{4}, \mathrm{Om}^{8}\right]$ oxytocin synthesized by V. J. Hruby (University of Arizona, Tucson, $A Z$ ) and characterized in our previous studies (Chan et al., 1986, 1990). It is a selective oxytocin- and $V_{1 a}$-receptor antagonist with no $\mathrm{V}_{2}$-receptor activity. The oxytocin used was Pitocin (Parke-Davis, Morris Plains, NJ). Diclofenac sodium was purchased from Sigma (St Louis, MO). Multilabelled [ $\left.{ }^{3} \mathrm{H}\right] \mathrm{PGF}_{2 \mathrm{o}}$ and $\left.{ }^{3} \mathrm{H}\right] \mathrm{PGE}_{2}$ were purchased from NEN DuPont (Boston, $\mathrm{MA}$ ). Anti-PGF ${ }_{2 \alpha^{\prime}}$ anti-PGE ${ }_{2}$ and prostaglandin standards were obtained from Advanced Magnetics (Cambridge, MA) and the Coat-A-Count Progesterone RIA kit from Diagnostic Products Corp. (Los Angeles, CA).

\section{Animals and experimental protocol}

Wistar rats, $200-225 \mathrm{~g}$, were purchased from Hilltop Laboratories (Scottsdale, PA). Only rats showing regular oestrous cycles were used. Pseudopregnancy was induced by gonadotrophin treatment followed by cervical stimulation as described by Rao and Gibor (1987). At metoestrus, 50 iu PMSG wash injected s.c.; this was followed $56 \mathrm{~h}$ later by 50 iu hCG. Sixteen hours after hCG injection, cervical stimulation was applied with a glass rod. When the vaginal smear showed primarily leucocytic infiltration on the next day, the rat was considered at day $I$ of pseudopregnancy. Vaginal smears were taken and examined every morning for each rat. The day before the next emergence of oestrus was considered as the last day of pseudopregnancy. On day 6 of pseudopregnancy, rats were randomly assigned to one of three groups. (i) The oxytocintreated group was given $500 \mathrm{mU}$ oxytocin (Pitocin: $10 \mathrm{U} \mathrm{ml}^{-1}$, diluted in saline), injected s.c. twice a day at $09.00 \mathrm{~h}$ and $17.00 \mathrm{~h}$ on days 6,7 and 8. (ii) The control group was given saline injections at the same time. Four of the controls also carried a saline-filled osmotic pump as described below. (iii) The oxytocin and oxytocin antagonist-treated group was given the same dose of oxytocin but was also given a continuous infusion of an oxytocin antagonist, $\left[\mathrm{Pen}^{1}, \mathrm{Phe}(\mathrm{Me})^{2}, \mathrm{Thr}^{4}, \mathrm{Om}^{8}\right]$ oxytocin, delivered by an Alzet micro-osmotic pump, model 1003D (Alza, Palo Alto, CA), implanted s.c. over the neck and shoulder region, at a rate of $300 \mu \mathrm{g}$ day ${ }^{-1}$ from days 6 to 8 . The oxytocin antagonist was dissolved and diluted in $0.25 \%$ acetic acid. The micro-osmotic pump had a delivery capacity of 3-3.5 days and was not removed on day 9. Twelve rats from each of the oxytocin-treated and control groups, and four rats from the oxytocin and oxytocin antagonist-treated group were observed to monitor the duration of pseudopregnancy. In addition, three or more rats from the oxytocin-treated and the control groups were killed on each of days 2, 6, 7, 9, 11 and 13 between 09.00 and $10.00 \mathrm{~h}$ to obtain tissue and blood specimens for determinations of luteal and uterine prostaglandin concentrations and plasma progesterone concentrations. Under surgical depth anaesthesia with $4 \%$ isoflurane (Anaquest, Madison, WI), the uterus and ovaries were quickly removed and a heparinized blood sample was obtained by cardiac puncture. The animal was then killed by an anaesthetic overdose. The uterus and ovaries were placed in ice-cold $0.9 \% \mathrm{NaCl}$ containing $10 \mu \mathrm{g}$ of diclofenac sodium $\mathrm{ml}^{-1}$, a potent cyclooxygenase inhibitor, to suppress prostaglandin synthesis. The uterus was dissected clean, blotted on a filter paper and its weight determined. It was then frozen in liquid nitrogen until used for prostaglandin extractions. The ovaries were dissected at ice-cold temperature under a dissecting microscope and the large corpora lutea of pseudopregnancy were harvested as described by Olofsson and Selstam (1988). The wet weight of the harvested corpora lutea was determined and the tissue frozen in liquid nitrogen until used for prostaglandin extraction. The blood sample was centrifuged at $4000 \mathrm{~g}$ for $20 \mathrm{~min}$ at $4{ }^{\circ} \mathrm{C}$ and the plasma stored frozen until used for progesterone determination by radioimmunoassay.

\section{Determinations of progesterone and prostaglandins}

Plasma progesterone concentration was determined directly without extraction by radioimmunoassay with a Coat-A-Count progesterone radioimmunoassay kit. The progesterone RIA kit was highly specific for progesterone with low crossreactivities, $<2.0 \%$ for $20 \alpha$-dihydroprogesterone and deoxycorticosterone and $<1.0 \%$ for other steroids normally in the plasma. The radioimmunoassay kit was validated in our laboratory with two concentrations of progesterone in plasma from male rats. The recovery was between 110 and $120 \%$. Luteal and uterine $\mathrm{PGF}_{2 \alpha}$ and $\mathrm{PGE}_{2}$ contents were extracted and eluted through a Sep-Pak $\mathrm{C}_{18}$ cartridge (Waters, Milford, MA) with an acidic ethyl acetate system before radioimmunoassays. Extractions of tissue prostaglandin were carried out by homogenizing the tissue in $50 \%$ isopropyl alcohol in phosphate buffer, $\mathrm{pH} 7.4$, with a Polytron homogenizer (Brinkmann Instruments, Westbury, NY). An equal volume of phosphate buffer was added to the homogenate and mixed in a shaker for $10 \mathrm{~min}$. The homogenate was then centrifuged at $4000 \mathrm{~g}$ for $30 \mathrm{~min}$. The supernatant was acidified to $\mathrm{pH} 3-4$ with $10 \%$ formic acid for extraction with a Sep-Pak $C_{18}$ cartridge. The Sep-Pak was washed with $2.0 \mathrm{ml}$ methanol and conditioned with the acidified alcoholic buffer, $\mathrm{pH} 3-4$. The supernatant was then passed through the Sep-Pak twice; washed with $5.0 \mathrm{ml}$ water and $2.0 \mathrm{ml}$ hexane, and then eluted with $5.0 \mathrm{ml}$ ethyl acetate. The resultant prostaglandin extract was dried at $40^{\circ} \mathrm{C}$ under nitrogen. The residue was stored at $-20^{\circ} \mathrm{C}$ until used for radioimmunoassay. Details of this extraction method and the prostaglandin radioimmunoassay system have been described by Chan (1987). Each sample was measured in duplicate and at two different dilutions. The antisera were highly specific for $\mathrm{PGE}_{2}$ or $\mathrm{PGF}_{2 \alpha}$ with low crossreactivities: for the anti-PGE $2^{\prime}<1.5 \%$ with $\mathrm{PGF}_{2 \alpha}$ and $<1.0 \%$ 


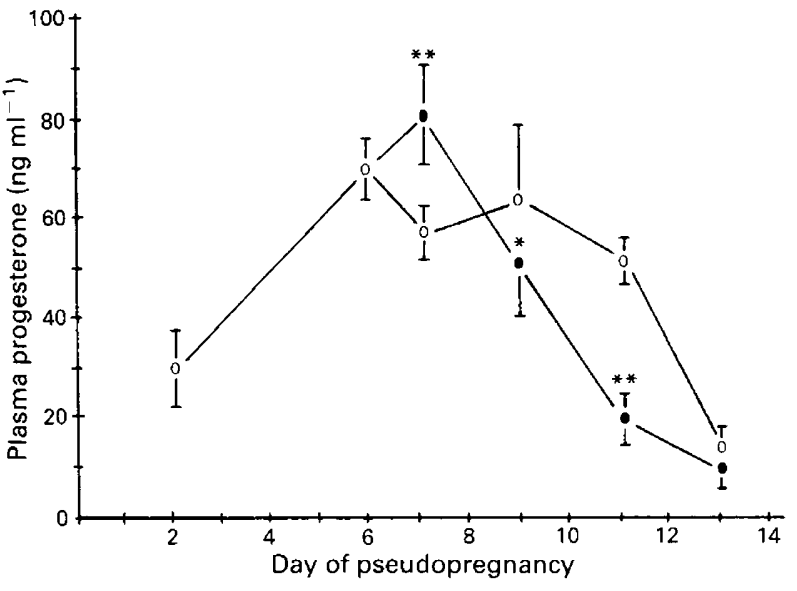

Fig. 1. Concentrations of progesterone in plasma of $(O)$ control and (O) oxytocin-treated rats during the course of pseudopregnancy. Each point represents the mean \pm SEM of four pseudopregnant rats (except days 2 and $11, n=3$ ). Oxytocin-treated rats were given oxytocin $500 \mathrm{mU}$ s.c. twice a day from day 6 to day 8. Control rats were given saline. Day 11 was the last day of pseudopregnancy for the oxytocintreated rats. *Significantly different from the corresponding control $(P<0.05) ;{ }^{* *}$ significantly different from the corresponding control $(P<0.01)$.

for other prostaglandins relevant to the uterus; for the anti$\mathrm{PGF}_{2 \alpha^{\prime}}<0.5 \%$ with $\mathrm{PGE}_{2}$ and $<0.1 \%$ for other relevant prostaglandins. The sensitivity of the radioimmunoassay for progesterone was $50 \mathrm{pg} \mathrm{ml}^{-1}$ and for the prostaglandins $15 \mathrm{pg}$ $\mathrm{ml}^{-1}$. The intra-assay and interassay coefficients of variation were $<10 \%$ and $<15 \%$, respectively.

\section{Statistical analysis}

All data are expressed as sample or group means \pm SEM and analysed by analysis of variance. Difference between group means were analysed by Student's $t$ test and considered significant when $P<0.05$.

\section{Results}

\section{Effects of oxytocin on the duration of pseudopregnancy}

Pseudopregnancy was induced with gonadotrophin treatment followed by cervical stimulation in normal cyclic rats with more than $90 \%$ success rate. In 12 controls, the mean duration of pseudopregnancy was $13.5 \pm 0.3$ days. There was no difference between the eight saline injection only controls and the four injection plus pump controls. Oxytocin injections, $500 \mathrm{mU}$ s.c. twice a day, from day 6 to day 8 of pseudopregnancy reduced the duration of pseudopregnancy. In 12 oxytocintreated rats, the mean duration of pseudopregnancy was $11.5 \pm 0.3$ days. The difference between the two groups was statistically significant $(P<0.01)$.

The oxytocin-induced shortening of pseudopregnancy was associated with a premature fall in concentrations of progesterone in plasma, occurring two days earlier than in the control group. An initial increase in plasma progesterone concentrations following oxytocin injection was observed before the rapid fall in plasma progesterone (Fig. 1).

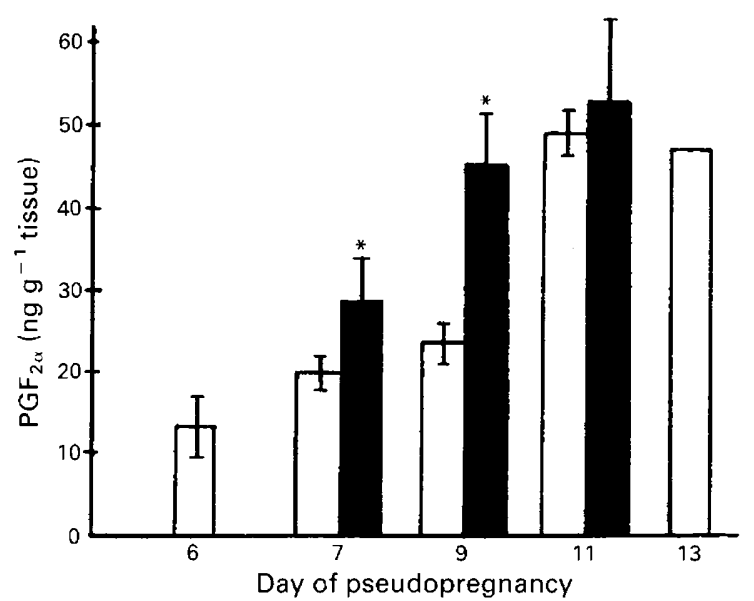

Fig. 2. Concentrations of PGF $_{2 a}$ in uterus of $(\square)$ control and ( $\square$ ) oxytocin-treated rats during the course of pseudopregnancy. Each bar represents the mean \pm SEM of four rats (except day $6, n=3$ ). Oxytocin-treated rats were given $500 \mathrm{mU}$ oxytocin s.c. twice a day from day 6 to day 8 . Control rats were given saline. ${ }^{*}$ Significantly different from the corresponding control $(P<0.05)$.

\section{Effects of oxytocin on uterine and luteal prostaglandin contents}

Uterine $\mathrm{PGF}_{2 \alpha}$ concentrations increased during the second half of pseudopregnancy. There was a gradual increase in uterine $\mathrm{PGF}_{2 \alpha}$ concentrations when measured on day 6 , day 7 and day 9 and a marked increase on day 11 and day 13 (Fig. 2). The $\mathrm{PGF}_{2 \alpha}$ concentrations on day 11 and day 13 were four times higher than concentrations on day 6. Oxytocin treatment stimulated uterine $\mathrm{PGF}_{2 \alpha}$ synthesis. Uterine $\mathrm{PGF}_{2 \alpha}$ concentrations on day 7 and day 9 of oxytocin-treated rats were significantly higher than the corresponding controls $(P<0.05)$.

Luteal $\mathrm{PGF}_{2 \alpha}$ concentrations on day 6 were slightly higher than the corresponding uterine PGF $_{2 a}$ concentrations, but the difference was not statistically significant. Luteal $\mathrm{PGF}_{2 \alpha}$ concentrations remained relatively stable when determined on day 6 , day 7 and day 9 . On day 11 , the $\mathrm{PGF}_{2 \alpha}$ concentration was twice the day 6 value (Fig. 3). Oxytocin treatment had no significant effect on luteal $\mathrm{PGF}_{2 \alpha}$ concentrations.

As expected, uterine $\mathrm{PGE}_{2}$ concentrations were low. Luteal $\mathrm{PGE}_{2}$ concentrations were high and comparable to the $\mathrm{PGF}_{2 \alpha}$ values. Neither uterine nor luteal $\mathrm{PGE}_{2}$ concentrations underwent significant changes during luteolysis (Fig. 4). Oxytocin treatment had no effect on $\mathrm{PGE}_{2}$ synthesis, except on day II when luteal $\mathrm{PGE}_{2}$ concentrations of the oxytocin-treated rats were significantly higher than the corresponding control values $(P<0.05)$.

\section{Effect of oxytocin antagonist}

In four pseudopregnant rats, $\left[\mathrm{Pen}^{1}, \mathrm{Phe}(\mathrm{Me})^{2}, \mathrm{Thr}^{4}, \mathrm{Orn}^{8}\right]-$ oxytocin, a specific oxytocin receptor antagonist, was administered with oxytocin. Oxytocin $500 \mathrm{mU}$ was injected s.c. twice a day from day 6 to day 8 . The oxytocin antagonist $(300 \mu \mathrm{g}$ day $^{-1}$ ) was delivered by a micro-osmotic pump also from day 6 to day 8 . The oxytocin antagonist protected the oxytocintreated rats from the luteolytic action of oxytocin. The mean 


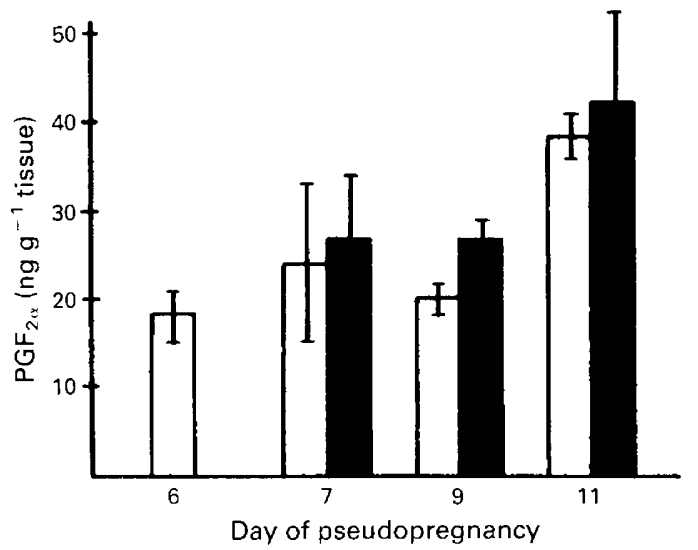

Fig. 3. Luteal concentrations of $\mathrm{PGF}_{2 \alpha}$ in ( $\square$ ) control and ( $\square$ ) oxytocinreated rats during the course of pseudopregnancy. Each bar represents the mean \pm SEM of four rats (except day $6, n=3$ ). Oxytocin-treated rats were given $500 \mathrm{mU}$ oxytocin s.c. twice a day from day 6 to day 8 . Control rats were given saline.

duration of pseudopregnancy of the rats treated with oxytocin and oxytocin antagonist was not different from that of the normal pseudopregnant rats (Table 1).

\section{Discussion}

There is substantial experimental evidence suggesting that oxytocin has a role in luteolysis in domestic ruminants. It is not known whether oxytocin has a similar role in rodents. In the study reported here, we demonstrated that oxytocin was also luteolytic in the pseudopregnant rat. Injections of oxytocin from day 6 to day 8 of pseudopregnancy resulted in a premature termination of pseudopregnancy. The mean duration of pseudopregnancy of the normal controls in our study was 13.5 days. In the oxytocin-treated rats, it was shortened to 11.5 days. We did not administer oxytocin treatment until day 6 of pseudopregnancy, since newly formed corpora lutea are known to be resistant to the luteolytic action of $\mathrm{PGF}_{2 \alpha}$ (Behrman et al., 1979). In ewes, it has also been shown that the responsiveness of the uterine PGF secretory system to oxytocin developed only shortly before the onset of luteal regression (Fairclough et al., 1984; Silvia et al., 1992). If oxytocin treatment could be initiated earlier in the pseudopregnant rats, it could produce a more dramatic effect.

The oxytocin-induced termination of pseudopregnancy was associated with a functional regression of the corpus luteum as reflected by the decline in plasma progesterone concentrations. In oxytocin-treated rats, there was also a premature fall in concentrations of progesterone in plasma by 2 days. Oxytocin treatment induced an initial increase in circulating progesterone before the precipitous fall. The mechanism of this stimulation is unknown. As the increase in progesterone secretion of the control pseudopregnant rats appeared to reach a plateau between day 6 and day 9 , the day 7 progesterone value of the oxytocintreated rats might, in fact, be within the same range. However, other investigators have reported that oxytocin stimulates progesterone release in luteal cells in vitro (Jarry et al., 1990; Musah et al., 1990; Miyamoto and Schams, 1991) and in pigs at midoestrous cycle (Kieborz et al., 1991). The physiological significance of this oxytocin action is unclear to us. It has been hypothesized that oxytocin may be a luteotrophic factor stimulating progesterone secretion during the early oestrous period, but is luteolytic in the late luteal period (Homeida and Khalafalla, 1987; Miyamoto and Schams, 1991; Homeida and Al-Eknah, 1992).

Measurements of uterine and luteal prostaglandin contents in our experiments provide evidence that oxytocin-induced luteolysis in rats probably also involves uterine $\mathrm{PGF}_{2 \alpha}$ as the luteolysin. Uterine $\mathrm{PGF}_{2 a^{\prime}}$ but not $\mathrm{PGE}_{2^{\prime}}$ was found to increase with spontaneous luteolysis. Oxytocin treatment stimulated uterine $\mathrm{PGF}_{2 \alpha}$ synthesis. Increase in uterine $\mathrm{PGF}_{2 \alpha}$ concentrations in the oxytocin-treated rats was advanced by 2 days, the same duration by which pseudopregnancy was shortened. Thus, there was a close temporal correlation between oxytocininduced termination of pseudopregnancy and oxytocin-induced stimulation of uterine $\mathrm{PGF}_{2 a}$ synthesis. Luteal $\mathrm{PGF}_{2 \alpha}$ concentrations measured on day 6,7 and 9 were found to be in a similar range to uterine $\mathrm{PGF}_{2 \alpha}$. On day 11 , the $\mathrm{PGF}_{2 \alpha}$ concentration was twice the day 6 value. Oxytocin treatment had no significant effect on luteal $\mathrm{PGF}_{2 \alpha}$ concentrations. Thus, our findings suggest that oxytocin induces luteolysis in pseudopregnant rats, probably indirectly via uterine $\mathrm{PGF}_{2 \alpha}$ release, as in the ruminants. Our observations are consistent with earlier studies that have suggested a role for the uterus and $\mathrm{PGF}_{2 \mathrm{a}}$ in the regulation of luteolysis in rats. Hysterectomy and inhibition of prostaglandin synthesis by indomethacin were found to increase the duration of pseudopregnancy in rats (Melampy et al., 1964; Lau et al., 1975). Measuring peripheral plasma concentrations of $\mathrm{PGE}_{2^{\prime}} \mathrm{PGF}_{2 \alpha}$ and progesterone in pseudopregnant rats, Saksena et al. (1974) concluded that an increase in the plasma concentration of $\mathrm{PGF}_{2 \alpha}$ on day 7 was the cause of the gradual decline in peripheral progesterone concentrations. These earlier studies also found no correlation between PGE $_{2}$ and peripheral progesterone. Thus, our findings together with those earlier studies strongly suggest that, in rats, as in ruminants, uterine $\mathrm{PGF}_{2 \alpha}$ is the prime initiator of luteolysis. Oxytocin induces luteolysis in pseudopregnant rats indirectly via its action on releasing uterine $\mathrm{PGF}_{2 a}$. This interpretation is consistent with findings by Mukhopadhyay et al. (1984) and Olofsson et al. (1992) which showed that oxytocin had no effects on luteal progesterone and prostaglandin secretion in vitro.

Luteal $\mathrm{PGE}_{2}$ concentrations were four to five times higher than that found for the uterus and were in the same concentration range as were luteal $\mathrm{PGF}_{2 a}$. There was no clear increase in uterine or luteal $\mathrm{PGE}_{2}$ synthesis during luteolysis. However, on day 11 , there was an increase in luteal $\mathrm{PGE}_{2}$ concentration of the oxytocin-treated rats. The difference between the oxytocintreated rats and the control rats was statistically significant $(P<0.05)$. The luteal prostaglandin profiles during pseudopregnancy observed in our study were similar to those reported by Olofsson and Norjavaara (1990). The high concentrations of luteal $\mathrm{PGE}_{2}$ and its function in luteolysis are not understood. The authors have suggested that concentrations of luteal $\mathrm{PGE}_{2}$ are kept high to ensure further $\mathrm{PGF}_{2 \alpha}$ formation in the regressing corpus luteum via the $\mathrm{PGE}_{2}-9$-keto-reductase pathway. These same authors also concluded from their study that the increase in luteal $\mathrm{PGF}_{2 \alpha}$ during luteolysis can be intrinsically 


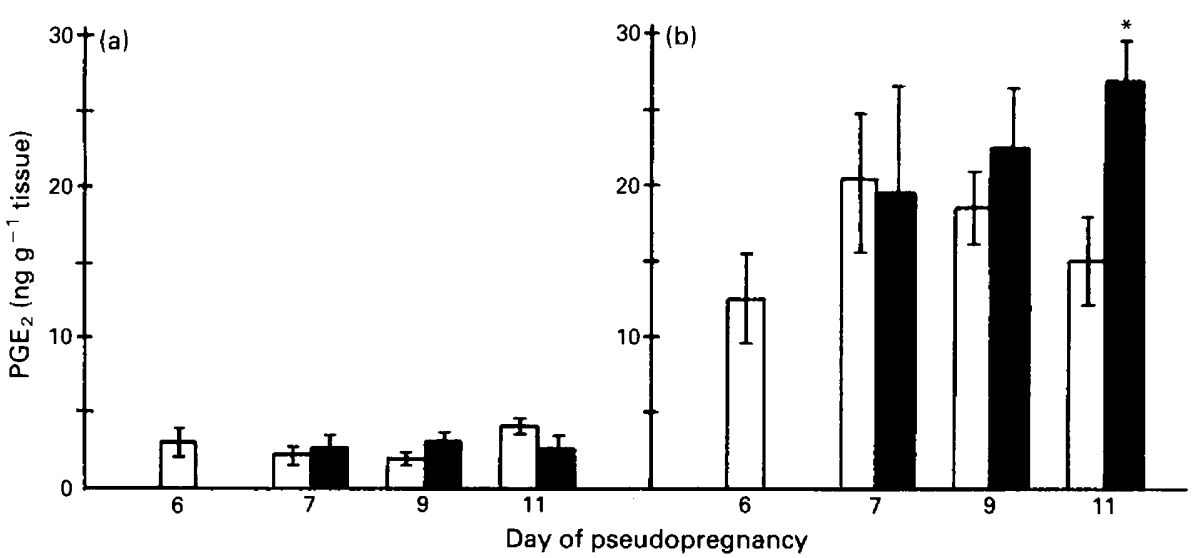

Fig. 4. Uterine and luteal concentrations of $\mathrm{PGE}_{2}$ in $(\square)$ control and ( $\square$ ) oxytocin-treated rats during the course of pseudopregnancy. (a) uterine $\mathrm{PGE}_{2}$ (b) luteal $\mathrm{PGE}_{2}$. Each bar represents the mean \pm SEM of four rats (except day 6,n=3). Oxytocin-treated rats were given $500 \mathrm{mU}$ oxytocin s.c. twice a day from day 6 to day 8 . Control rats were given saline. ${ }^{*}$ Significantly different from the corresponding control $(P<0.05)$.

Table 1. Antagonism of the luteolytic action of oxytocin by a specific oxytocin receptor antagonist in pseudopregnant rats

\begin{tabular}{lcc}
\hline Treatment & $n$ & $\begin{array}{c}\text { Duration of } \\
\text { pseudopregnancy } \\
\text { (days) }\end{array}$ \\
\hline $\begin{array}{l}\text { Control } \\
\begin{array}{l}\text { Oxytocin } \\
\text { Oxytocin antagonist and } \\
\text { oxytocin }\end{array}\end{array}$ & 12 & $11.3 \pm 0.3$ \\
\hline
\end{tabular}

Values shown are means \pm SEM; $n=$ number of rats in group.

*Significantly different from the control and the OT antagonist plus OT groups $(P<0.01)$.

accomplished by the corpus luteum and that luteal $\mathrm{PGF}_{2 \alpha}$ could be a physiological signal for luteolysis in rats. However, Weems (1979) showed that in pseudopregnant rats with bilateral deciduomata, luteal maintenance was extended for approximately the same time as the duration of gestation with no inhibition of $\mathrm{PGF}_{2 \alpha}$ secretion. The author concluded that extended luteal function by deciduomal tissue occurred by some mechanism other than an inhibition of $\mathrm{PGF}_{2 \alpha}$ secretion. This finding would suggest that uterine or luteal $\mathrm{PGF}_{2 a}$ is important only in luteolysis of nonpregnant rats.

The oxytocin-induced luteolysis, reducing of the duration of pseudopregnancy, appeared to be mediated by the oxytocin receptor, as the action was blocked by the co-administration of a specific oxytocin receptor antagonist. The doses of oxytocin used in this study were pharmacological concentrations. Whether oxytocin is normally involved in luteolysis in rats is not known. For domestic ruminants, it is generally believed that ovarian oxytocin secreted by the corpus luteum is the endogenous oxytocin involved in luteolysis (Flint and Sheldrick, 1983; Wathes, 1984; Flint et al., 1990). In goats, intra-arterial administration of an oxytocin antagonist between days 12 and 20 of the oestrous cycle delay luteal regression (Homeida and Khalafalla, 1987). Human and rat ovaries also produce oxytocin (Wathes et al., 1982; Khan-Dawood and Dawood, 1983; Dawood and Khan-Dawood, 1986; Wolf et al., 1986; Ho and Lee, 1992). However, the physiological functions of ovarian oxytocin in primates and rats are not understood. Wolf $e t$ al. (1986) found a decreased secretion rate of ovarian oxytocin at pro-oestrus and oestrus in rats when blood concentration of prolactin was increased. Ho and Lee (1992), however, found that the ovarian content of oxytocin was tenfold higher at oestrus than at other phases. These two authors suggested that rat ovarian oxytocin may participate in the ovulatory process as well as in the luteolytic process. Concentrations of oxytocin in plasma show no significant changes during the oestrous cycle. This finding suggests that ovarian oxytocin, not pituitary oxytocin, is probably involved in the regulation of luteal functions. The physiology of ovarian oxytocin in luteal functions merits further study.

This work was supported, in part, by USPHS Grant HD-20839. The authors wish to thank $\mathrm{T}$. Cooper for her excellent technical assistance in this study.

\section{References}

Bazer FW (1992) Mediators of maternal recognition of pregnancy in mammals Proceedings of the Society for Experimental Biology and Medicine 199 373-384

Behrman HR, Luborsky-Moore JL, Pang CY, Wright K and Dorflinger LJ (1979) Mechanisms of $\mathrm{PGF}_{2 \alpha}$ action in functional luteolysis Advances in Experimental Medicine and Biology 112 557-575

Challis JRG, Calder AA, Dilley S, Forster CS, Hillier K, Hunter DJS, Mackenzie IZ and Thorburn GD (1977) Production of prostaglandins $E$ and $F_{2 a}$ by corpora lutea, corpora albicantes and stroma from the human ovary Joumal of Endocrinology 68 401-408

Chan WY (1987) Enhanced prostaglandin synthesis in the parturient rat uterus and its effects on myometrial oxytocin receptor concentrations Prostaglandins 34 889-902

Chan WY, Hruby VJ, Rockway TW and Hlavacek J (1986) Design of oxytocin antagonists with prolonged action: potential tocolytic agents for the treatment of preterm labor Journal of Pharmacology and Experimental Therapeutics $23984-87$ 
Chan WY, Cao L, Hill PS and Hruby VJ (1990) Oxytocin- and vasopressinbinding sites in the rat uterus: competition binding and inhibitory $\mathrm{pA}_{2}$ studies with oxytocin and oxytocin antagonist Endocrinology 126 2095-2101

Dawood MY and Khan-Dawood FS (1986) Human ovarian oxytocin: its source and relationship to steroid hormones American Journal of Obstetrics and Gynecology 154 756-763

Fairclough RJ, Moore LG and McGowan LT (1980) Temporal relationship between plasma concentrations of 13,14-dihydro-15-keto-prostaglandin $\mathrm{F}$ and neurophysin I/II around luteolysis in sheep Prostaglandins 20 199-208

Fairclough RJ, Moore LJ, Peterson AJ and Watkins WB (1984) Effect of oxytocin on plasma concentrations of 13,14-dihydro-prostaglandin F and oxytocinassociated neurophysin during the estrous cycle and early pregnancy in the ewe Biology of Reproduction 31 36-43

Flint APF and Sheldrick EL (1982) Ovarian secretion of oxytocin is stimulated by prostaglandins Nature $297587-588$

Flint APF and Sheldrick EL (1983) Evidence for a systemic role for ovarian oxytocin in luteal regression in sheep Journal of Reproduction and Fertility 67 $215-225$

Flint APF, Sheldrick EL, McCann TJ and Jones DSC (1990) Luteal oxytocin: characteristics and control of synchronous episodes of oxytocin and $\mathrm{PGF}_{20}$ secretion at luteolysis in ruminants Domestic Animal Endocrinology 7 111-124

Ho M-L and Lee J-N (1992) Ovarian and circulating levels of oxytocin and arginine vasopressin during the estrous cycle in the rat Acta Endocrinologica $126530-534$

Homeida AM and Al-Eknah MM (1992) Inhibition of luteal function by oxytocin antagonist in goats (Capra hircus) Journal of Reproduction and Fertility 94 279-285

Homeida AM and Khalafalla AE (1987) Effect of oxytocin-antagonist injections on luteal regression in the goat British Journal of Pharmacology 90 281-284

Hooper SB, Watkins WB and Thorburn GD (1986) Oxytocin, oxytocin-associated neurophysin, and prostaglandin $\mathrm{F}_{2 \alpha}$ concentrations in the utero-ovarian vein of pregnant and nonpregnant sheep Endocrinology 119 2590-2597

Jarry H, Einspanier A, Kanngieber L, Dietrich M, Pitzel L, Hostz W and Wuttke W (1990) Release and effects of oxytocin on estradiol and progesterone secretion in porcine corpora lutea as measured by an in vivo microdialysis system Endocrinology 126 2350-2358

Khan-Dawood FS and Dawood MY (1983) Human ovaries contain immunoreactive oxytocin Journal of Clinical Endocrinology and Metabolism 57 $1129-1132$

Kieborz KR, Silvia WJ and Edgerton LA (1991) Changes in uterine secretion of prostaglandin $F_{2 \alpha}$ and luteal secretion of progesterone in response to oxytocin during the porcine estrous cycle Biology of Reproduction 45 950-954

Lamsa JC, Kot SJ, Eldering JA, Nay MG and McCracken JA (1989) Prostaglandin $\mathrm{F}_{20}$-stimulated release of ovarian oxytocin in the sheep in vivo: threshold and dose dependency Biology of Reproduction 40 1215-1223

Lau I-F, Saksena SK and Chang MC (1975) Effect of indomethacin, an inhibitor of prostaglandin biosynthesis on the length of pseudopregnancy in rats and hamsters Acta Endocrinologica 78 343-348

Melampy RM, Anderson LL and Kragt CL (1964) Uterus and life span of rat corpora lutea Endocrinology 74 501-504

Miyamoto A and Schams D (1991) Oxytocin stimulates progesterone release from microdialyzed bovine corpus luteum in vitro. Biology of Reproduction 44 1163-1170

Moore LG, Choy VJ, Elliot RL and Watkins WB (1986) Evidence for the pulsatile release of $\mathrm{PGF}_{2 \alpha}$ inducing the release of ovarian oxytocin during luteolysis in the ewe Joumal of Reproduction and Fertility 76 159-166

Mukhopadhyay AK, Kumar A, Tams R, Bohnet HG and Leidenberger FA (1984) Oxytocin and vasopressin have no effect on progesterone production and cyclic AMP accumulation by rat luteal cells in vitro Journal of Reproduction and Fertility 72 137-141

Musah AI, Schwabe C and Anderson LL (1990) Relaxin, oxytocin, and prostaglandin effects on progesterone secretion from bovine luteal cells during different stages of gestation Proceedings of the Society for Experimental Biology and Medicine 195 255-260

Olofsson J and Norjavaara E (1990) Effects of hysterectomy and uterine decidualization on in vivo levels of prostaglandins in the corpus luteum of adult pseudopregnant rats Biology of Reproduction 43 762-768

Olofsson J and Selstam G (1988) Changes in corpus luteum content of prostaglandin $\mathrm{F}_{2 \alpha}$ and $\mathrm{E}$ in the aduit pseudopregnant rat Prostaglandins 35 $31-40$

Olofsson J, Norjavaara $\mathrm{E}$ and Selstam $\mathrm{G}$ (1990) In vivo levels of prostaglandin $\mathrm{F}_{2 \alpha^{\prime}}$ $\mathrm{E}_{2}$ and prostacyclin in the corpus luteum of pregnant and pseudopregnant rats Biology of Reproduction 42 792-800

Olofsson J, Norjavaara E and Selstam G (1992) Synthesis of prostaglandin $F_{2 a}$ and $E_{2}$ and prostacyclin in isolated corpora lutea of adult pseudopregnant rats throughout the luteal life-span Prostaglandins Leukotrienes and Essential Fatty Acids 46 151-161

Rao MC and Gibor G (1987) Corpus luteum: arimal models: possible relevance to reproductive toxicology Reproductive Toxicology $161-69$

Richardson MC (1986) Hormonal control of ovarian luteal cells Oxford Reviews of Reproductive Biology 8 321-378

Saksena SK, Watson DT, Lau I-F and Shaikh AA (1974) Peripheral plasma levels of $E$ and $F$ series prostaglandins during pseudopregnancy in the rat Prostaglandins 5 557-565

Silvia WJ and Taylor ML (1989) Relationship between uterine secretion of prostaglandin $\mathrm{F}_{2 a}$ induced by oxytocin and endogenous concentrations of estradiol and progesterone at three stages of the bovine estrous cycle Journal of Animal Science 67 2347-2353

Silvia WJ, Lewis GS, McCracken JA, Thatcher WW and Wilson L, Jr (1991) Hormonal regulation of uterine secretion of prostaglandin $F_{2 a}$ during luteolysis in ruminants Biology of Reproduction 45 655-663

Silvia WJ, Raw RE, Aldrich SL and Hayes SH (1992) Uterine secretion of prostaglandin $\mathrm{F}_{2 a}$ in response to oxytocin in ewes: changes during the estrous cycle and early pregnancy Biology of Reproduction 46 1007-1015

Swanston IA, McNatty KP and Baird DT (1977) Concentration of prostaglandin $F_{2 a}$ and steroids in human corpus luteum Joumal of Endocrinology 73 115-122

Wathes DC (1984) Possible actions of gonadal oxytocin and vasopressin Journal of Reproduction and Fertility 71 315-345

Wathes DC, Swann RW, Pickering BT, Porter DG, Hull MGR and Drife JU (1982) Neurohypophyseal hormones in the human ovary Lancet ii 410-412

Watkins WB and Moore LG (1987) Effect of systemic intravenous infusion of $\mathrm{PGF}_{2 a}$ and 13,14-dihydro-15-keto-PGF ${ }_{z a}$ on the release of oxytocinassociated neurophysin from the ovary in the ewe Journal of Reproduction and Fertility 80 105-112

Webb R, Mitchell MD, Falconer J and Robinson JS (1981) Temporal relationships between peripheral plasma concentrations of oxytocin, progesterone and 13,14-dihydro-15-keto-prostaglandin $F_{2 a}$ during the oestrus cycle and early pregnancy in the ewe Prostaglandins 22 443-453

Weems CW (1979) Prostaglandins F in uterine and ovarian compartments and in plasma from the uterine vein, ovarian artery and vein, and abdominal aorta of pseudopregnant rats with and without deciduomata Prostaglandins 17 $873-890$

Wolf R, Meier-Fleitmann A, Duker E-M and Wuttke W (1986) Intraovarian secretion of catecholamines, oxytocin, beta-endorphin, and gamma-aminobutyric-acid in freely moving rats: development of a push-pull tubing method Biology of Reproduction 35 599-607 